Review Article
J Exp Clin Med

2021; 38(S2): 175-179

doi: 10.52142/omujecm.38.si.dent.16

\title{
What does complete digital workflow mean for dentistry?
}

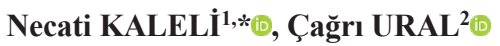 \\ ${ }^{1}$ Department of Dentistry Services, Vocational School of Health Services, Ondokuz Mayıs University, Samsun, Turkey \\ ${ }^{2}$ Department of Prosthodontics, Faculty of Dentistry, Ondokuz Mayıs University, Samsun, Turkey
}

\author{
$\begin{array}{lllll}\text { Received: } 10.09 .2020 & \bullet & \text { Accepted/Published Online: } 18.11 .2020 & \bullet & \text { Final Version: } 19.05 .2021\end{array}$
}

\begin{abstract}
The introduction of computer-aided manufacturing technologies and further developments have changed the routine workflow in dentistry, and dentists are now rapidly shifting from conventional to digital. As a result, intra-oral scanners have become a standard device in dental clinics even though they have a considerable cost. One of the important reasons of this digital transition is to ensure standardized-quality manufacturing with a shorter chair time, which is promised by complete digital workflow. So, what does complete digital workflow mean for dentistry? This review elaborately answers to this question and summarizes the stages of complete digital workflow in dental applications.
\end{abstract}

Keywords: complete digital workflow, computer-aided manufacturing, digital dentistry, digital impression

\section{Introduction}

The introduction of computer-aided design and computeraided manufacturing (CAD-CAM) systems along with technological developments in the $21^{\text {st }}$ century have completely changed the world and started the digital revolution. In this new digital age, software's are constantly being updated, and new technological developments emerge with each passing day. However, the main question is that What does digital mean? Digital can be theoretically defined as the data processing between the 1 and 0 , but literally means the way to do more with less effort (Dörner and Edelman, 2015). As for dentistry, it means science-based planning, standardized quality and reproducibility in manufacturing, ease of communication, shorter chair time, patient comfort and satisfaction, predictable treatment results, continuous and objective education, and auto-controlled treatment modality (Mangano et al., 2017; Rekow, 2020).

The decision of which stage the digital workflow will be used at is up to the dentists. Dentists may whether to proceed digitally after the impression process (semi-digital workflow) or from the beginning of treatment (complete digital workflow) (Joda et al., 2017c). Complete digital workflow followed in fabrication of both tooth-borne and implant-supported restorations consists of three stages: (1) digitization of intraoral structures or prosthetic components (2) computer-aided design (CAD), (3) computer-aided manufacturing (CAM) (Alghazzawi, 2016). This workflow also involves a computeraided implant surgery (CAIS) stage in implant treatments, and there is a lot of research on this subject (Widmann and Bale, 2006; Arisan et al., 2010a; Arısan et al., 2010b; Stapleton et al., 2014; Coachman et al., 2017; Joda et al., 2018)

Complete digital workflow can be perfectly utilized if the dentists and dental technicians follow the true guidelines, know the limitations of the system that they used, and act as a team. This review briefly explains the stages and limitations of complete digital workflow in both tooth-borne and implantsupported restorations (Fig. 1).

\section{Computer-aided implant surgery}

To ensure the optimum esthetic outcomes, dental implants should be placed in ideal position (Grunder et al., 2005). In single implant sites, the implants should be placed 1.5 to $2 \mathrm{~mm}$ more palatal than the expected buccal emergence profile and 3 $\mathrm{mm}$ more apical to cemento-enamel junction of adjacent teeth (Buser et al., 2004), and at least $1.5 \mathrm{~mm}$ away from the adjacent teeth (Esposito et al., 1993). Also, the minimum inter-implant distance should be $3 \mathrm{~mm}$ when the multiple implants are placed (Tarnow et al., 2000). In free-handed implant surgeries, adjacent teeth act as natural guides for correct positioning. However, the ideal positioning of dental implants is challenging in edentulous jaws due to lack of anatomical landmarks. (Arısan et al., 2010b). The use of surgical implant guides provides significant advantages in such cases (Arısan et al., 2010a). The fabrication of surgical guides can be conducted with complete digital workflow and this includes several steps 
as follows: (1) intra-oral scanning and exporting the scan data as standard tessellation language (.stl) file format, (2) conebeam computed tomography (CBCT) evaluation and exporting the DICOM data, (3) superimposition of .stl and DICOM data by using the guide software, (4) virtual set-up, (5) virtual positioning of implants, (6) exporting and fabrication of threedimensional (3D) guide model (Margvelashvili-Malament and Att, 2019). This workflow is defined as static computer-aided implant surgery (s-CAIS) (Joda et al., 2018; Tahmaseb et al., 2018). Moreover, the virtual positioning of implant can be conducted by using denture-like radiographic templates, which includes radiopaque landmarks, and this is also called prosthetically driven and computer guided implant planning or prosthetically driven implant surgery (Katsoulis et al., 2009; D'haese et al., 2017). An alternative digital workflow for implant surgeries is the dynamic navigation systems, which are based on motion-tracking technology. The navigation systems allow real-time tracking of implant drills (D'haese et al., 2017). Dynamic navigation also allows changing the surgical plan, and this is an important advantage for the benefit of patients (Block and Emery, 2016).

\section{COMPLETE DIGITAL WORKFLOW} IN DENTISTRY

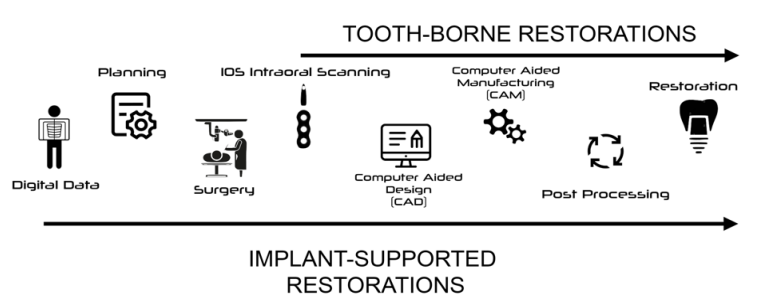

Fig. 1. Complete digital workflow in dentistry

\section{Intra-oral digitization}

In tooth-borne restorations, the complete digital workflow begins with the use of intraoral scanner (IOS), and this is termed as computer-aided impressioning (CAI) (Patzelt et al., 2013). CAI eliminates the expansion, shrinkage, and distortion of both cast models and elastomeric impressions and offers a repeatable workflow (Patzelt et al., 2014a; Ting-Shu and Jian, 2015; Mangano et al., 2017). Today, many dental clinics use the IOSs in routine clinical practice. Dentists, who consider buying an IOS, question digital impressions in terms of accuracy, time efficiency, and patient comfort. In the available literature, sufficient data exist that answer to these questions.

Several studies evaluated the accuracy of digital impressions, and the common view is that single-tooth or partial-arch impressions are a valid alternative to conventional impressions, whereas the full-arch digital impressions are still questionable (Ender et al., 2016a; Ender et al., 2016b; Ahlholm et al., 2018; Ender et al., 2019), and this is also valid for fullarch implant impressions (Ender and Mehl, 2015; Mangano et al., 2017).
In digital implant impressions, scan bodies are used instead of impression copings, which are used in conventional implant impressions. A scan body simply consists of three parts: upper part (scan region), middle part (body), and apical part (base) (Fig. 2). The base part can be metal, titanium (Ti) or polyetheretherketone (PEEK), whereas the scan region is mostly PEEK (Mizumoto and Yilmaz, 2018). One of the main advantages of the digital implant impressions with scan bodies is that angulation of implants has no significant effect on impression accuracy (Giménez et al., 2015). However, the visibility of the scan bodies may have an impact on accuracy, particularly when the implants are deeply placed. Moreover, it has been reported that the first scanned quadrant achieves better accuracy than the second quadrant; and therefore, it is recommended to start the scanning process from the restoration site in partial restorations (Gimenez-Gonzalez et al., 2017).

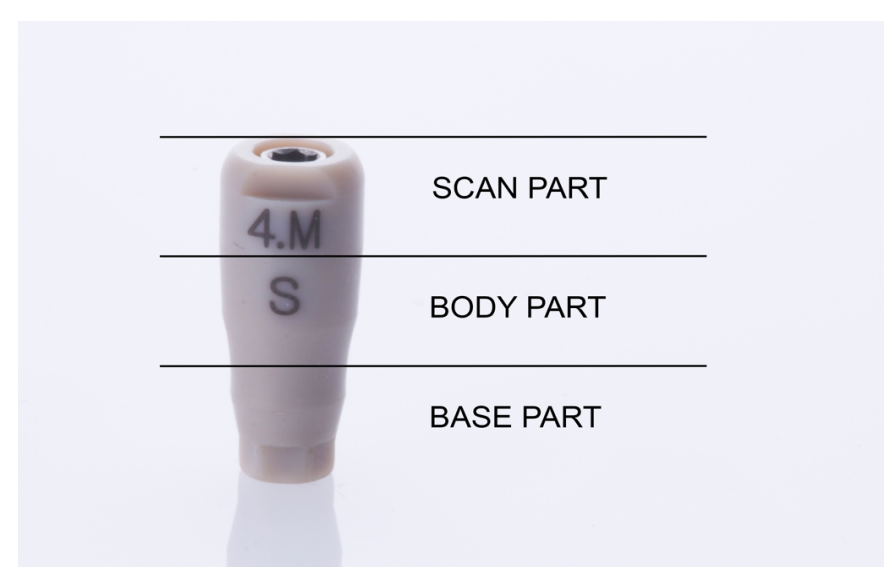

Fig. 2. Parts of implant scan bodies

Furthermore, the scanning strategies and scanning software's also influence the accuracy of digital impressions (Ender and Mehl, 2013; Haddadi et al., 2018; Ender et al., 2019). The scanning strategies are specific to the IOS system; and therefore, clinicians should follow the manufacturer's guidelines to obtain optimum accuracy results (Ender et al., 2019).

As for time efficiency and patient comfort, digital impression techniques have been reported to be preferable in tooth-borne restorations (Patzelt et al., 2014b; Yuzbasioglu et al., 2014), and in single-implant cases. A quadrant-like intraoral scanning process is sufficient to record the single-implant sites rather than taking full-arch conventional impressions (Joda and Brägger, 2015; Joda et al., 2017b; Mühlemann et al., 2018). However, this may not be valid for full-arch digital implant impressions (Sailer et al., 2019). Besides, time efficiency and patient comfort is up to the dentists' skills and experience as well (Giménez et al., 2015; Gimenez-Gonzalez et al., 2017). The duration of scanning process may prolong in the first digital impression trials and prolonged impression time may discomfort patients, but over time this will gradually decrease parallel to the learning curve (Mangano et al., 2017). 


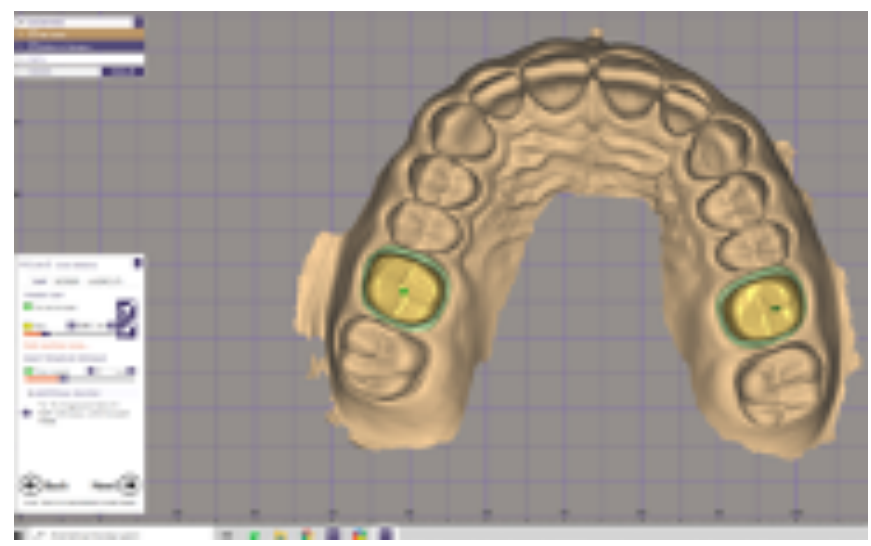

Fig. 3. Designing parameters in $\mathrm{CAD}$ software

\section{Digital design process}

Once the digital impression process is completed, the scan data can be directly transferred to milling device, if available in the clinic, or sent to the dental laboratory via the IOS's software network (Selz et al., 2016). Another option is to export the scan data as .stl file format and send to the laboratory via internet network (Ting-Shu and Jian, 2015; Alghazzawi, 2016). Today, a majority of IOS manufacturers allows to export stl files, and this makes the digital workflow more accessible. When the designer technician imported the stl file into the CAD software, another adventure begins. The CAD software automatically creates a crown morphology over the prepared tooth or implant abutment; however, each design should be modified manually because the tooth morphology is unique for each patient. One of the important advantages of digital design is that the CAD software allows the designer to imitate the individual morphological features, particularly in the occlusal region, by selecting the biogeneric copy tool (Alghazzawi, 2016). Thus, restorations can be designed according to habitual occlusion of each patient. Also, the designer can control several parameters (Fig. 3), such as the level of adjacent and antagonist contacts, cement film thickness, and margin design (Tapiea et al., 2015). These parameters can be set according to the clinicians' requests. Moreover, the current CAD software's include virtual articulator and facebow modules (Fig. 4), which allow to adjust the occlusal contacts in accordance with actual mandibular movements, and this minimizes the final occlusal adjustments in the patients' mouth.

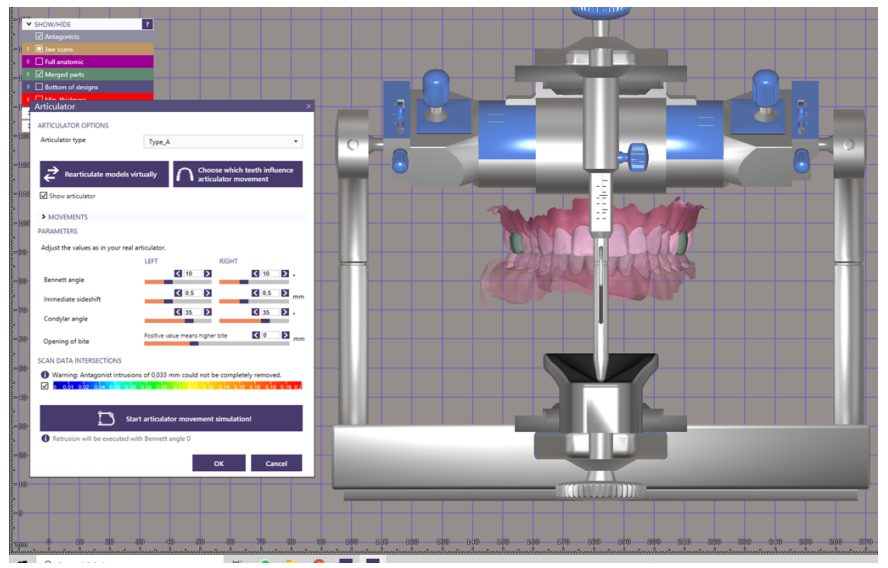

Fig. 4. Use of virtual articulator module in CAD software

\section{Digital manufacturing}

Computer-aided manufacturing is the last stage of the complete digital workflow. In this stage, the CAD data transform into an actual restoration. This process can be conducted by using subtractive or additive manufacturing systems (Van Noort, 2012; Alghazzawi, 2016). In subtractive manufacturing, the restorations are fabricated by milling (metal, zirconia, PMMA, composite resin) or grinding (ceramics) large solid blocks with using sharp cutting tools (Alghazzawi, 2016). Unlike subtractive systems, additive manufacturing is the process based on joining materials to fabricate objects from 3D models (Van Noort, 2012; Alghazzawi, 2016). Which system to use generally depends on the material used and the workflow followed. With the spread of the complete digital workflow in dentistry, the use of monolithic restorations has increased (Joda and Brägger, 2016; Joda et al., 2017a; De Angelis et al., 2020), and this requires the use of milling systems. Currently, additive manufacturing is not a valid method for processing dental ceramics. Additive manufacturing solutions are generally used in direct metal laser sintering/melting of metal frameworks and 3D printing of temporary restorations, complete dentures, digital models, surgical guides, custom trays, and wax patterns (Van Noort, 2012; Alghazzawi, 2016).

The design and manufacturing stages of complete digital workflow can be completed in either dental clinics or dental laboratories. Dental clinics may have their own design software and milling systems, and thus, they can have the chance to fabricate ceramic restorations on the same day along with tooth preparations, that is also called as chairside workflow (Fasbinder, 2006; Fasbinder, 2013). However, milling machines, which are promoted for dental clinics, generally have four axes milling units and less cutting tools; therefore, the milling accuracy is lower than five axes milling units, which are used in dental laboratories (Alghazzawi, 2016). For this reason, chairside workflow is not efficient in all cases, particularly in fabrication of full-arch restorations, which need high milling precision. Full-arch restorations are mostly fabricated in dental laboratories because they provide industrial manufacturing solutions with high precision rate (Miyazaki and Hotta, 2011; Alghazzawi, 2016).

\section{Conclusion}

The digital workflow journey involves several steps, and each step has its own learning curve. Clinicians and dental technicians must know the limitations of the system they used, and they should be patient to gain a certain level of experience. Computer-aided dentistry constantly evolves, and software's are updated day by day. To improve the accuracy and feasibility of digital workflow, manufacturers require technical and clinical feedbacks. If the clinicians report the clinical outcomes in a constructive manner, many problems experienced in the complete digital workflow would be overcome in the future. 


\section{References}

1. Ahlholm, P., Sipilä, K., Vallittu, P., Jakonen, M., Kotiranta, U., 2018. Digital versus conventional impressions in fixed prosthodontics: A review. J. Prosthodont. 27, 35-41.

2. Alghazzawi, T.F., 2016. Advancements in CAD/CAM technology: Options for practical implementation. J. Prosthodont. Res. 60, 7284.

3. Arısan, V., Karabuda, C.Z., Özdemir, T., 2010a. Implant surgery using bone and mucosa supported stereolithographic guides in totally edentulous jaws: Surgical and post-operative outcomes of computer aided vs. standard techniques. Clin. Oral. Implants. Res. 21, 980-988.

4. Arısan, V., Karabuda, Z.C., Özdemir, T., 2010b. Accuracy of two stereolithographic guide systems for computer aided implant placement: a computed tomography based clinical comparative study. J. Periodontol. 81, 43-51.

5. Block, M.S., Emery, R.W., 2016. Static or dynamic navigation for implant placement choosing the method of guidance. J. Oral Maxillofac. Surg. 74, 269-277.

6. Buser, D., Martin, W., Belser, U.C., 2004. Optimizing esthetics for implant restorations in the anterior maxilla: anatomic and surgical considerations. Int. J. Oral. Maxillofac. Implants. 19, 43-61.

7. Coachman, C., Calamita, M.A., Coachman, F.G., Coachman, R.G., Sesma, N., 2017. Facially generated and cephalometric guided 3D digital design for complete mouth implant rehabilitation: A clinical report. J. Prosthet. Dent. 117, 577-586.

8. D'haese, J., Ackhurst, J., Wismeijer, D., De Bruyn, H., Tahmaseb, A., 2017. Current state of the art of computer guided implant surgery. Periodontol. 2000. 73, 121-133.

9. De Angelis, P., Passarelli, P.C., Gasparini, G., Boniello, R., D'amato, G., De Angelis, S., 2020. Monolithic CAD-CAM lithium disilicate versus monolithic CAD-CAM zirconia for single implant-supported posterior crowns using a digital workflow: A 3year cross-sectional retrospective study. J. Prosthet. Dent. 123, 252-256.

10. Dörner, K., Edelman, D., 2015. What 'digital'really means. McKinsey Digital. Dostępny w Internecie: https://www. mckinsey. com/industries/high-tech/our-insights/what-digital-really-means.

11. Ender, A., Attin, T., Mehl, A., 2016a. In vivo precision of conventional and digital methods of obtaining complete-arch dental impressions. J. Prosthet. Dent. 115, 313-320.

12. Ender, A., Mehl, A., 2013. Influence of scanning strategies on the accuracy of digital intraoral scanning systems. Int. J. Comput. Dent. 16, 11-21.

13. Ender, A., Mehl, A., 2015. In-vitro evaluation of the accuracy of conventional and digital methods of obtaining full-arch dental impressions. Quintessence. Int. 46, 9-17.

14. Ender, A., Zimmermann, M., Attin, T., Mehl, A., 2016b. In vivo precision of conventional and digital methods for obtaining quadrant dental impressions. Clin. Oral. Investig. 20, 1495-1504.

15. Ender, A., Zimmermann, M., Mehl, A., 2019. Accuracy of complete-and partial-arch impressions of actual intraoral scanning systems in vitro. Int. J. Comput. Dent. 22, 11-19.

16. Esposito, M., Ekestubbe, A., Gröndahl, K., 1993. Radiological evaluation of marginal bone loss at tooth surfaces facing single Brånemark implants. Clin. Oral. Implants. Res. 4, 151-157.

17. Fasbinder, D.J., 2006. Clinical performance of chairside CAD/CAM restorations. The J. Am. Dent. Assoc. 137, 22-31.

18. Fasbinder, D.J., 2013. Computerized technology for restorative dentistry. Am. J. Dent. 26, 115-120.
19. Giménez, B., Özcan, M., Martínez-Rus, F., Pradíes, G., 2015. Accuracy of a digital impression system based on active wavefront sampling technology for implants considering operator experience, implant angulation, and depth. Clin. Implant. Dent. Relat. Res. 17, e54-e64.

20. Gimenez-Gonzalez, B., Hassan, B., Özcan, M., Pradíes, G., 2017. An in vitro study of factors influencing the performance of digital intraoral impressions operating on active wavefront sampling technology with multiple implants in the edentulous maxilla. J. Prosthodont. 26, 650-655.

21. Grunder, U., Gracis, S., Capelli, M., 2005. Influence of the 3-D bone to implant relationship on esthetics. Int. J. Periodontics. Restorative. Dent. 25, 113-119.

22. Haddadi, Y., Bahrami, G., Isidor, F., 2018. Effect of software version on the accuracy of an intraoral scanning device. Int. J. Prosthodont. 31, 375-376.

23. Joda, T., Brägger, U., 2015. Digital vs. conventional implant prosthetic workflows: A cost/time analysis. Clin. Oral. Implants. Res. 26, 1430-1435.

24. Joda, T., Brägger, U., 2016. Time efficiency analysis of the treatment with monolithic implant crowns in a digital workflow: a randomized controlled trial. Clin. Oral. Implants. Res. 27, 14011406.

25. Joda, T., Derksen, W., Wittneben, J.G., Kuehl, S., 2018. Static computer aided implant surgery (s-CAIS) analysing patient reported outcome measures (PROMs), economics and surgical complications: A systematic review. Clin. Oral. Implants. Res. 29, 359-373.

26. Joda, T., Ferrari, M., Brägger, U., 2017a. Monolithic implant supported lithium disilicate (LS2) crowns in a complete digital workflow: A prospective clinical trial with a 2 year follow up. Clin. Implant. Dent. Relat. Res. 19, 505-511.

27. Joda, T., Lenherr, P., Dedem, P., Kovaltschuk, I., Bragger, U., Zitzmann, N.U., 2017b. Time efficiency, difficulty, and operator's preference comparing digital and conventional implant impressions: A randomized controlled trial. Clin. Oral. Implants. Res. 28, 1318-1323.

28. Joda, T., Zarone, F., Ferrari, M., 2017c. The complete digital workflow in fixed prosthodontics: A systematic review. BMC. Oral. Health. 17, 124.

29. Katsoulis, J., Pazera, P., Mericske Stern, R., 2009. Prosthetically driven, computer guided implant planning for the edentulous maxilla: a model study. Clin. Implant. Dent. Relat. Res. 11, 238245 .

30. Mangano, F., Gandolfi, A., Luongo, G., Logozzo, S., 2017. Intraoral scanners in dentistry: A review of the current literature. BMC. Oral. Health. 17, 149.

31. Margvelashvili-Malament, M., Att, W., 2019. Current workflows for computer-aided implant surgery: A review article. Curr. Oral. Health. Rep. 6, 295-305.

32. Miyazaki, T., Hotta, Y., 2011. CAD/CAM systems available for the fabrication of crown and bridge restorations. Aust. Dent. J. 56, 97106.

33. Mizumoto, R.M., Yilmaz, B., 2018. Intraoral scan bodies in implant dentistry: A systematic review. J. Prosthet. Dent. 120, 343352 .

34. Mühlemann, S., Kraus, R.D., Hämmerle, C.H., Thoma, D.S., 2018. Is the use of digital technologies for the fabrication of implant supported reconstructions more efficient and/or more effective than conventional techniques: A systematic review. Clin. Oral. Implants. Res. 29, 184-195. 


\section{Kaleli and Ural / J Exp Clin Med}

35. Patzelt, S.B., Emmanouilidi, A., Stampf, S., Strub, J.R., Att, W., 2014a. Accuracy of full-arch scans using intraoral scanners. Clin. Oral. Investig. 18, 1687-1694.

36. Patzelt, S.B., Lamprinos, C., Stampf, S., Att, W., 2014b. The time efficiency of intraoral scanners: an in vitro comparative study. J. Am. Dent. Assoc. 145, 542-551.

37. Patzelt, S.B., Vonau, S., Stampf, S., Att, W., 2013. Assessing the feasibility and accuracy of digitizing edentulous jaws J. Am. Dent. Assoc. 144, 914-920.

38. Rekow, E.D., 2020. Digital dentistry: The new state of the art Is it disruptive or destructive? Dent. Mater. 36, 9-24.

39. Sailer, I., Mühlemann, S., Fehmer, V., Hämmerle, C.H., Benic, G.I., 2019. Randomized controlled clinical trial of digital and conventional workflows for the fabrication of zirconia-ceramic fixed partial dentures. Part I: Time efficiency of complete-arch digital scans versus conventional impressions. J. Prosthet. Dent. 121, 69-75.

40. Selz, C.F., Vuck, A., Guess, P.C., 2016. Full-mouth rehabilitation with monolithic CAD/CAM-fabricated hybrid and all-ceramic materials: A case report and 3-year follow up. Quintessence. Int. 47, 115-121.

41. Stapleton, B.M., Lin, W.S., Ntounis, A., Harris, B.T., Morton, D., 2014. Application of digital diagnostic impression, virtual planning, and computer guided implant surgery for a CAD/CAMfabricated, implant-supported fixed dental prosthesis: A clinical report. J. Prosthet. Dent. 112, 402-408.

42. Tahmaseb, A., Wu, V., Wismeijer, D., Coucke, W., Evans, C., 2018. The accuracy of static computer aided implant surgery: A systematic review and meta-analysis. Clin. Oral. Implants. Res. 29, 416-435.

43. Tapiea, L., Lebonb, N., Mawussic, B., Chabouisd, H.F., Durete, F., Attalf, J., 2015. Understanding dental CAD/CAM for restorations the digital workflow from a mechanical engineering viewpoint. Int. J. Comput. Dent. 18, 21-44.

44. Tarnow, D., Cho, S., Wallace, S., 2000. The effect of inter-implant distance on the height of inter implant bone crest. J. Periodontol. $71,546-549$

45. Ting-Shu, S., Jian, S., 2015. Intraoral digital impression technique: A review. J. Prosthodont. 24, 313-321.

46. Van Noort, R., 2012. The future of dental devices is digital. Dent. Mater. 28, 3-12.

47. Widmann, G., Bale, R.J., 2006. Accuracy in computer-aided implant surgery a review. Int. J. Oral. Maxillofac. Implants. 21, 305-313.

48. Yuzbasioglu, E., Kurt, H., Turunc, R., Bilir, H., 2014. Comparison of digital and conventional impression techniques: Evaluation of patients' perception, treatment comfort, effectiveness, and clinical outcomes. BMC. Oral. Health. 14, 10. 